Servicio de publicaciones y difusión científica (SPDC), Universidad de Las Palmas de Gran Canaria, Parque CientíficoTecnológico, Edificio Polivalente II, C/ Practicante Ignacio Rodríguez, s/n Campus Universitario de Tafira 35017 - Las Palmas de Gran Canaria, Spain.

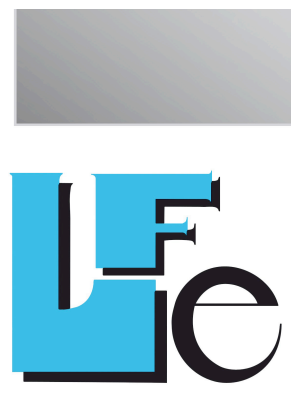

Revista de Lenguas para Fines Específicos

\section{Revista de lenguas para fines específicos}

eISSN: $2340-8561$

Journal information, indexing and abstracting details, archives, and instructions for submissions:

https://ojsspdc.ulpgc.es/ojs/index.php/LFE/index

\section{Book review: Kecskes, Istvan. 2014. Intercultural Pragmatics. Oxford: Oxford University Press, pp. 278.}

Roberto A. Valdeón

Universidad de Oviedo, Facultad de Filología, Campus El Milán, Oviedo, 33011 (Spain).

Article first published online: 27 July 2015.

Article published online with DOI added: 5 April 2016.

Revista de Lenguas para fines específicos is licensed under a Creative Commons ReconocimientoNoComercial-SinObraDerivada 4.0 Internacional License. 


\title{
Book review: Kecskes, Istvan. 2014. Intercultural Pragmatics. Oxford: Oxford University Press, pp. 278.
}

\author{
Roberto A. Valdeon ${ }^{1}$ \\ Universidad de Oviedo
}

Intercultural pragmatics aims to explore areas of pragmatics neglected in the literature until now. The view that intercultural exchange should be regarded as a normal success-and-failure process rather than as a collision is the starting point of the book, which sets out to investigate the pitfalls of L2 speakers using a language they may be less familiar with, and, above all, in a cultural context they may be less knowledgeable about. The author suggests that the differences between intercultural communication and intracultural communication may be less important than scholars admit.

Kecskes does not aim to change the definition of pragmatics as "a branch of linguistics that focuses on the use of language in social contexts and the ways in which people produce and comprehend meanings through language" (p.6) but rather the way we consider it. For that purpose he proposes what he calls a sociocognitive approach (p. 6-7), which relies on socio-cultural factors in order to understand the pragmatics of language. These are related to the speakers's past experience. In the author's view, prior knowledge would activate speaker responses in certain situations. Kecskes argues that there are three main approaches to the study of pragmatics, namely pragma-semantic, pragma-dialogue, and pragmadiscourse (p. 10-14) and contends that the last one is the best alternative to consider all the factors at play.

More interesting in the introduction is Kecskes' proposal of a third culture

\footnotetext{
Corresponding author - Universidad de Oviedo, Facultad de Filología, Campus El Milán, Oviedo, 33011 (Spain).

Email: valdeon@uniovi.es
} 
characteristic of the encounters where speakers belong to two distinct cultures. The concept is, of course, not new. At least two other disciplines, namely cultural studies and translation studies, have had recourse to the notion of the third space, defended by Bhaba among others. It is novel, though, to apply it to the study of pragmatics, as authors tend to focus on the contextual factors of a given culture. That third space would consider not only the utterances of the speakers, but also the discourse: "discourse focuses on an organized set of utterances" (p. 13). This third space, for which the author draws on Evanoff, is not the sum of anything, but rather a qualitatively different entity. Kecskes' definition of intercultural pragmatics comes next: "[it] is concerned with the way the language system is put to use in social encounters between human beings who have different first languages, communicate in a common language, and, usually, represent different cultures" ( $p$. 14). To examine intercultural pragmatics, the author draws on the concept of interculturality as an emergent and co-constructed phenomenon (p. 15) and aims to cover the peculiarities of the discipline, including issues such as cooperation, the role of individual factors, context-sensitivity and communicative strategies. None of these are, of course, new as they have been studied from different perspectives in recent decades. What is certainly innovative is the attempt to establish links between all of them.

In chapter one, Kecskes examines current pragmatic theories, and makes a distinction between approaches that focus on interpreting the codes, and those that take into account the socio-cultural context. The book will side with the latter, as it includes a "harmonious interplay between all three participating elements (speaker, code, context)" (p. 22). In the rest of the chapter, Kecskes presents the main differences between Anglo-American linguistic-philosophical pragmatics, which considers intention as the centre of the communication chain, and the socio-cultural paradigm, which underlines the equivocality of it (p. 25). Intercultural pragmatics tries to bridge the two traditions by directing attention to four major issues: intention, speaker meaning, cooperation versus egocentrism and contextdependency (p. 27). In order to do this, Kecskes claims, it is necessary to recontextualize intention to distinguish between speaker intended meaning and joint meaning pertaining to the interpersonal domain. Thus, he introduces the concept of "emergent intention" (p. 29), as factors such as loss of interest, language difficulty and so on can cause a change of intention. The author proposes what he terms an egocentric approach, which, in his view, is congruent with his own dynamic model of meaning (Kecskes 2008). Finally, he points out that any of theory of intercultural pragmatics needs to consider both the actual situational context and prior context, or the baggage that the speakers bring to communication.

Chapter 2 deals with the socio-cognitive approach to intercultural pragmatics, which 
takes into account both societal and individual factors. This refers to the "integrative and cognitive and social properties of systems, processes, functions, and models" (p. $42)$, and suggests that we should consider three types of knowledge, i.e. collective prior, individual prior and actual situationally created knowledge (p. 44), as part of the integrative model. Kecskes sensibly calls for the need to revise the idealized view of communication, which is a dynamic process in which participants intervene in two ways: they are constrained by societal factors, but they also shape them. In this sense, two concepts are important in communication: intention, which can be aprioristic but also emergent (or evolving) because this side of intention is coconstructed (p. 50-51); and attention, which is related to the concept of "egocentrism" (p. 52). This refers to the state of mind of the interlocutors and can cause variations in the communication process. Interlocutors are, thus, both cooperative (as regards intention) and egocentric (as regards attention) (p. 53). Salience is another important factor. This concept refers to the relative importance of signs, which can lead to misunderstandings. However, intercultural pragmatics should go beyond the study of misunderstandings in order to analyze other elements, for example people's reactions when misunderstandings do occur (p. 59).

In this chapter, as we have seen, the author uses and discusses what he terms "egocentrism", a word that refers to "attention-bias that is the result of prior experience of individuals" (p. 42). Although the term is clearly explained and used generously in this sense throughout the book, it might pose some difficulties to the readers. After all it is difficult to dissociate it from our prior knowledge and more general use of the word (social and individual) and to apply it in the very restrictive meaning found in the book. Kecskes also uses another term that may cause some confusion, i.e. privatized. It refers to collective knowledge that has been subjectivized by the individual (p. 45). Once again, whereas the explanation is clear, previous collective and individual knowledge might make it difficult for the readers to use it in this restricted and more technical sense.

Chapter 3 discusses an issue that, in Kecskes' view, has been largely neglected: the acquisition of intercultural competence. This is due to the fact that intercultural pragmatics focuses on its use rather than on its development. However, the author discusses a number of highly relevant points. For example, Kecskes claims that in intercultural communication the existing L1-based pragmatic competence is adjusted to the new environment (p. 61), making a distinction between language socialization, characteristic of the L1 (p. 63), and "conceptual socialization", which refers to the adaptation of the features of L1 pragmatics to the needs of the L2 ( $p$. 67). This is important, particularly when the foreign language is used as a lingua franca, because speakers may not have a good command of the language. In this situation, pragmatic mistakes are not perceived as serious because the interlocutors 
are likely to be aware of these shortcomings. The situation is more complex when the speaker is very fluent in the L2 (p. 65). Conceptual socialization, the author argues, is broader. Speakers are more aware of pragmatic issues in the L2, while age also plays a factor as well as the intensity of the contact with the target culture. Formulaic language is a way of dealing with L2 situations (p. 71) and, for this reason, it is of the utmost importance to study situation-bound utterances, as prefabricated pragmatic units are often related to specific communicative situations. These utterances have strong socio-cultural values (p. 74) and they may vary from culture to culture: some languages may deal with certain situations and rituals in specific ways (here the author uses the example of Turkish speakers, who have a standardized form to wish good luck to owners of new houses whereas other languages do not, p. 76).

The next chapter, devoted to encyclopedic knowledge, cultural models and interculturality, starts by discussing the concept of culture, once again regarded as a dynamic concept. Culture is related to encyclopedic knowledge in the sense of knowledge of the world rather than of language (p. 81). The combination of these would form what Kecskes labels conceptual system. Encyclopedic knowledge is considered a structured system that provides scenarios for individuals to interpret speech situations. The author relates this to how it is used in cognitive linguistics and proposes some distinctions, i. e. there is no principled distinction between semantics and pragmatics, there is no separation between prior knowledge and actual situational context (pp. 82-84). Kecskes concludes this chapter with the proposal of a third space (p. 97) characterized by intercultural exchanges, where interculturality is an "ad hoc creation", with apriori and emergent sides (p. 99). These are neither fixed nor permanent. The study of this third space can be achieved by paying attention to the selection of formulaic language of a language in order to differentiate intracultural from intercultural communication.

The discussion of formulaic language comes in chapter 5, which starts by stating that formulaic language is the heart and soul of native-like language (p. 105). This is further supported in the following pages, often by providing references to the author's own work and to definitions by Biber et al (1999), whose Grammar of Spoken and Written English has become a landmark in EFL. Kecskes himself acknowledges the importance of corpus linguistics, which he has used in a study of the discourse used by non-native speakers of English, which led him to conclude that L2 speakers use fewer instances of prefabricated expressions. In the discussion sessions that followed, the students claimed that they did not feel comfortable when using these formulas as native speakers might misunderstand them. The author stresses the importance of using the so-called situation-bound utterances (or SBUs), that is, prefabricated pragmatic units whose occurrences are tied to certain communicative 
situations (p. 122).

Chapter 6 delves into the concept of context. In intercultural communication, context can actually clarify the way in which two or more non-native speakers use English. Kecskes recalls the notion of the third space before he moves on to distinguish between its "two sides" (p. 131): prior context and actual situational context. The author proposes a Dynamic Model of Meaning (DMM) and context (pp. $137 \mathrm{ff}$ ), which he first introduced eight years earlier. This model takes heed both of prior and present experience to define the role of context. On p. 139 the author emphasizes that it is important to make a distinction between meaning of lexical units and situational meaning. Thus, meaning comes to be fully realized when speakers and listeners unpack previous experience. The former, also considered "coresense meaning" (p. 141), is abstracted from previous contextual occurrences of words. This would be objective as opposed to what the author calls "consense", which is subjective and changes as we move from context to context. Kecskes uses "lunch" and "almuerzo" to explain the difference. Thus, these items share a similar coresense but differ in the culture-specific conceptual properties, and it is the latter that can give way to serious misunderstandings in intercultural communication. For this reason, non-native speakers need to gain experience in order to avoid those communication breakdowns. They need a shared common ground, which is what he goes on to explore in the next chapter.

Intercultural speakers share a problem: their prior experiences differ. Common ground relates to prior and actual situational context as well as to cultural models, beliefs, etc. (p. 153). The author contends that the lack of this common ground becomes less of a problem as a result of the so-called emergent common ground, an area shared by non-native interlocutors as they construct their interculture. The lack of common ground can be the cause of conflict between speakers of different languages, as individuals tend to rely on their own "egocentric" knowledge rather than on mutual knowledge. Intercultural pragmatics can bridge this gap between interlocutors (p. 157), substantiated by a socio-cognitive approach. Additionally, the distinction between core common and emergent common ground can provide some explanation to the peculiarities of intercultural communication. The former tends to be static, although it may change diachronically. As Kecskes bases his approach on lexical items, he uses English examples to illustrate his point: the implications of the word gay, for instance, have changed over the years. On the other hand, emergent common ground is dependent on actual situations and change synchronically (p. 163). According to the author, three factors affect this: the activation of mental representations by the interlocutors, the search for information and existing previous knowledge (pp. 164-166). He also adds that intercultural pragmatics supports a "normal communication approach", which entails that 
interlocutors have their own problems and difficulties (p. 166) concerning, for instance, the use of formulaic language, which the book keeps discussing on different levels.

In the next chapter, Kecskes moves on to discuss salience, an element that gives prominence to the most significant features of communication, and, which, in pragmatics, entails linguistic as well as conceptual salience (p. 177). He adds that the socio-cognitive approach stresses the bidirectionality of both, and underlines that in linguistic research the tendency is to relate salience to the frontal position of some sentence elements. In the socio-cognitive approach proposed in the book, salience is an inherent property, but it is also emergent, as it depends on the situation and also on diachronic evolution. Here the author uses an example we have already seen, the lexical item "gay" (p. 183). Kecskes proposes three types of salience: inherent (related to the speaker), collective (related to the community) and emergent situational salience (related to the constraints of the situation). In the following pages, the author deals with salience in connection with linguistic research in a discussion that moves from functional to generative linguistics. Kecskes is fully aware of the relevance of the work by Halliday (p. 190), whose functional grammar resonates throughout the book. Halliday has, of course, been rather adamant to accept pragmatics as a separate discipline from linguistics, despite the explosion of publications and studies on the topic. In the final pages of the chapter, Kecskes stresses the importance of idiomatic expressions and makes a distinction between native and non-native speakers, as the former tend to rely on the literal meaning, whereas the latter do not. Thus, native speakers have a more holistic approach to these expressions, while non-natives are more analytic (p. 197). From here we move on to the last part of the book, devoted to politeness and impoliteness.

Chapter 9 reminds readers that most publications on politeness are "Anglocentered" (p. 201) and calls for the need to work on this area of research in intercultural encounters. Politeness and impoliteness studies have followed two main trends. One of them is the result of the discursive turn, with its focus on the participants' own assessment of what is polite and impolite (p. 202). The second one has used Brown and Levinson's concept of face. The first approach can offer a less essentialist view of politeness, as it questions the existence of norms as something fixed. However, it relies on the somehow limited methods of the second approach, namely conversation analysis and face-related terms. Kecskes views the emergent "genre approach" as more adequate for the study of politeness and impoliteness ( $p$. 205), which, in any case, should consider three issues: intention, norms and cultural models, and the role of context.

The book concludes with a short chapter, in which the authors briefly examines some of the methods that can be applied to the study of intercultural pragmatics, 
such as conversation analysis and corpus-based approaches, and an epilogue in which the author foresees a promising future for intercultural pragmatics. In a world dominated by the continuous movement of people who need to speak a language other than their own (often English, although other languages are becoming increasingly important), the author is undoubtedly right. And his book is likely to become widely quoted in an area of study that keeps growing through international conferences and journals.

\section{About the author}

Roberto A. Valdeon has a Master's degree in English Literature and Translation Studies (University of Glasgow) and a Ph. D. in English Studies (University of Oviedo). He has published extensively on translation, including contributions to journals such as Perspectives, Across Languages and Cultures, Meta, Language and Intercultural Communication, Terminology, Target, Babel, Translation Studies, Philological Quarterly, The Translator, Languages in Contrast, Intercultural Pragmatics, Bulletin of Spanish Studies and Translating and Interpreting Studies. He is a member of the international advisory board of Vigo International Journal of Applied Linguistics (University of Vigo) and John Benjamins's Handbook of Translation Studies and Forum. Since July 2011 he serves as Editor-in-Chief of Perspectives Studies in Translatology. He has been a visiting scholar at the University of Massachusetts Amherst (2011-2012 and 2014) and a visiting professor at the University of Leuven (2013). In 2013 Spain's Ministry of Education accredited him as Full Professor. He is also a Research Associate at the University of the Free State (South Africa) for the period 2015-2017.

\section{Review article history}

Review received: 9th January 2015

Review received in revised form and accepted for publication: 26th March 2015 


\section{References}

Biber, D., S. Johansson, G. Leech, S. Conrad \& E. Finegan. (1999). Longman Grammar of Spoken and Written English. Harlow: Longman. 